\title{
Exploring the mid-load potential of ethanol-diesel dual-fuel combustion with and without EGR
}

Vinícius B. Pedrozo, lan May, Hua Zhao

Centre for Advanced Powertrain and Fuels Research (CAPF), Brunel University London, Kingston Lane, Uxbridge, Middlesex UB8 3PH, United Kingdom

*Corresponding author. E-mail address: vinicius.pedrozo@brunel.ac.uk (V. B. Pedrozo).

\section{Highlights}

- Optimised diesel injection timings were identified for efficient dual-fuel combustion.

- A pre-injection of diesel prior to the main injection was essential to reduce PRR.

- High ethanol energy fractions effectively lowered NOx emissions.

- EGR further reduced NOx emissions with negligible impact on the engine efficiency.

- Operational cost savings can be achieved and are heavily dependent on fuel prices.

\section{Keywords}

Dual-fuel combustion; ethanol; alternative fuel; diesel engine; exhaust emissions; EGR. 


\section{Glossary}

ATDC, After Firing Top Dead Centre; CA10, Crank Angle of 10\% Cumulative Heat Release; CA10-CA50, 10-50\% Cumulative Heat Release; CA10-CA90, Combustion Duration or 10-90\% Cumulative Heat Release; CA50, Crank Angle of 50\% Cumulative Heat Release; CAD, Crank Angle Degree; CO, Carbon Monoxide; $\mathrm{CO}_{2}$, Carbon Dioxide; COV_IMEP, Coefficient of Variation of IMEP; DAQ, Data Acquisition; DF, Dual-Fuel; DPF, Diesel Particulate Filter; E85, Gasoline with 85\% ethanol in a volume basis; ECR, Effective Compression Ratio; ECU, Engine Control Unit; EF, Ethanol Energy Fraction; EGR, Exhaust Gas Recirculation; FID, Flame Ionisation Detector; FSN, Filter Smoke Number; HC, Hydrocarbons; HRR, Apparent Net Heat Release Rate; IMEP, Net Indicated Mean Effective Pressure; ISCO, Net Indicated Specific Emissions of CO; ISHC, Net Indicated Specific Emissions of the Actual Unburnt HC; ISNOx, Net Indicated Specific Emissions of NOx; ISsoot, Net Indicated Specific Emissions of Soot; IVC, Intake Valve Closing; IVO, Intake Valve Opening; $L H V_{C O}$, Lower Heating Value of Carbon Monoxide; $L H V_{D F}$ Lower Heating Value in

Dual-fuel Combustion Mode; $L H V_{\text {diesel }}$, Lower Heating Value of Diesel; $L H V_{\text {ethanol }}$, Lower Heating Value of Ethanol; $\dot{m}_{\text {diesel }}$, Mass Flow Rate of Diesel; $\dot{m}_{\text {ethanol }}$, Mass Flow Rate of Ethanol; $\dot{m}_{\text {urea }}$, Mass Flow Rate of Urea; MFB, Mass Fraction Burnt; NOx, Nitrogen Oxides; $\mathrm{O}_{2}$, Oxygen; $P_{i}$, Net Indicated Power; PFI, Port Fuel Injector; Pmax, Maximum In-cylinder Pressure; PMEP, Pumping Mean Effective Pressure; PRR, Pressure Rise Rate; RCCI, Reactivity Controlled Compression Ignition; SCR, Selective Catalytic Reduction; SOC, Start of Combustion; SOl's, Start of Injection Events; SOI_main, Actual Start of Main Injection; SOI_pre, Actual Start of Pre-injection; TDC, Top Dead Centre; VPR, Actual Volumetric Price Ratio; $V P R_{\max }$, Maximum Volumetric Price Ratio; VVA, Variable Valve Actuation; $\gamma$, Ratio of Specific Heats; $\Phi_{\text {global, }}$ Global Fuel/Air Equivalence Ratio. 


\section{Abstract}

Dual-fuel combustion has been shown as an effective means to maximise the utilisation of low carbon fuels in conventional diesel engines while simultaneously reducing nitrogen oxides (NOx) and soot emissions. In this framework, a systematic study was performed to optimise the use of ethanol as a partial substitute for diesel fuel and improve the effectiveness of dual-fuel combustion in terms of emissions, efficiency, and operational cost. Investigations were carried out on a singlecylinder common rail heavy-duty diesel engine at three mid-loads of $0.9,1.2$, and $1.5 \mathrm{MPa}$ net indicated mean effective pressure (IMEP). The ethanol energy fraction was varied from $0 \%$ to $80 \%$ and diesel injection timings were optimised for maximum efficiency. The experiments were conducted with and without cooled exhaust gas recirculation (EGR) to explore the trade-off between exhaust emissions and engine running costs. The results showed the importance of a small pre-injection of diesel prior to the main injection to reduce in-cylinder pressure rise rates (PRR). The use of high ethanol fractions resulted in shorter and delayed combustion process, similar indicated efficiency, and up to $68 \%$ lower NOx emissions than conventional diesel combustion. Soot levels varied with different ethanol percentages. Unburnt hydrocarbon (HC) and carbon monoxide (CO) emissions increased with higher amounts of premixed ethanol fuel. The introduction of $25 \%$ EGR led to further NOx reductions, decreasing the nitrogen oxides levels of the non-EGR cases by $80 \%$, on average, with little impact on engine efficiency. The overall results indicated that the utilisation of an ethanol fraction of $80 \%$ combined with EGR has potential to achieve $88 \%$ NOx reduction compared with the baseline conventional diesel combustion without EGR at 1.2 MPa IMEP. A cost-benefit analysis showed that the effectiveness of dual-fuel combustion in terms of cost is heavily dependent on fuel prices (e.g. per litre). The combustion strategy requires a maximum volumetric price ratio between ethanol and diesel fuels equivalent to $60 \%$. Higher relative prices can still be cost-effective depending on the ethanol energy fraction and EGR rate used as a result of reduced aqueous urea solution consumption in the NOx aftertreatment system. 


\section{Introduction}

Global energy demand for the transport sector has experienced significant growth over the last decade and is expected to increase by approximately $30 \%$ from 2014 to 2040 , with the vast majority of energy needs met by oil [1]. A projected rise in the number of cars and heavy-duty vehicles as well as the increased demand for other commercial transportation (e.g. airplanes, ships, and trains) is likely to offset the improvements in fuel conversion efficiency. Higher efficiency is generally achieved by advances in technology, which are mostly driven by ever more stringent emissions and fuel efficiency regulations.

Some examples of improvements introduced to heavy-duty diesel engines are high-pressure fuel injection systems, variable valve actuation (VVA) systems, variable geometry turbochargers, as well as diesel particulate filters (DPF) and selective catalytic reduction (SCR) aftertreatment systems. However, these technologies often cause manufacturing costs to rise for these engines [2]. The consumption of aqueous urea solution in the SCR system also affects the total cost of ownership, as the required flow rate is equivalent to $2-5 \%$ of diesel fuel use [3-6]. Therefore, it is favourable to reduce emissions and increase engine efficiency via the development of alternative combustion strategies and optimisation of the in-cylinder combustion process.

Advanced combustion strategies have demonstrated potential benefits over conventional diesel combustion and standard spark ignition combustion [7]. One effective approach is the dual-fuel combustion mode, which allows for the use of alternative low carbon fuels in diesel engines while improving efficiency and reducing NOx emissions [8,9]. The dual-fuel combustion also introduces significant soot reduction compared with conventional diesel combustion, particularly at elevated EGR rates $[10,11]$. As a result, fuel energy supply is diversified, production and running costs can be reduced, and air quality and subsequent effects to human health are improved. 
Dual-fuel combustion can be achieved by the port fuel injection (PFI) of ethanol, natural gas, etc. and direct injections of diesel. The combustion phasing is typically controlled by the diesel injection timing. However, the majority of the dual-fuel research has been performed with constant combustion phasing $[12,13]$ or fixed diesel injection timing [14], resulting in non-optimised engine efficiency and exhaust emissions. Tutak [15] showed that the use of a constant start of injection can lead to in over-retarded dual-fuel combustion and misfiring at high substitution ratios. The investigation was carried out on a high compression ratio diesel engine equipped with port fuel injection of E85, a blend of $85 \%$ ethanol and $15 \%$ gasoline. Moreover, non-optimised diesel injection timings can limit the premixed fuel fraction as a result of high pressure rise rates, as shown in the experimental work of Sarjovaara and Larmi [16]. The authors reported the autoignition of the E85 during the premixed combustion phase, which increased the PRR and limited the maximum substitution ratio to $34 \%$. This was possibly driven by the high intake air temperatures. Further investigations at the same mid-load [17] revealed that lower intake air temperatures can minimise the auto-ignition of the premixed fuel and delay the combustion phasing. This allowed for the use of a higher E85 energy fraction of $74 \%$.

Another means of reducing excessive PPR and extending the operating range for dual-fuel combustion is the introduction of large amounts of EGR into the engine $[13,18]$. High levels of EGR are often employed on a variant of the dual-fuel combustion technology referred to Reactivity Controlled Compression Ignition $(\mathrm{RCCl})$. This strategy relies on different in-cylinder fuel blending to generate fuel reactivity gradients that result in control over the combustion event [19-23]. However, high EGR rates might not be practical due to a great demand on the boosting system to maintain a reasonable air-fuel ratio and avoid excessive smoke as well as fuel economy penalty. Peak in-cylinder pressure is another constraint at higher engine loads when increasing total intake charge pressure [24]. In an attempt to decrease the EGR requirements, Asad et al. [25] demonstrated that ethanol fuel can be used in place of EGR to reduce NOx emissions for diesel low temperature combustion. Hanson et al. [26] revealed that minimum EGR rates can still reduce 
NOx emissions while minimising the consumption of aqueous urea solution in the SCR system and the impact on efficiency of a natural gas-diesel dual-fuel engine.

Therefore, optimisation of the dual-fuel combustion using high ethanol energy fractions and low-

moderate levels of EGR is needed to balance out high PRR's, NOx reduction capability, and running costs of SCR equipped vehicles. The current study experimentally explored the potential of ethanol-diesel dual-fuel combustion with and without EGR at mid-loads, where combustion efficiency and maximum in-cylinder pressure limit are less likely to affect engine performance [27]. The effects of different ethanol energy fractions on combustion, emissions, and efficiency have been investigated. The experiments were performed on a heavy-duty diesel engine with a geometric compression ratio of 16.8:1.

The novelty of the present research activity consists mainly on the use of optimised diesel injection timings for maximum indicated efficiency rather than a constant combustion phasing or start of injection. In particular, a small amount of diesel was injected prior to the main injection to shorten the ignition delay and maintain PRR below 2.0 MPa/CAD. In the last section, a cost-benefit and overall emissions analysis was carried out to determine the effectiveness of the use of ethanol and EGR on a heavy-duty diesel engine in terms of emissions, efficiency, and operational cost. The consumption of aqueous urea solution was estimated and the sensitivity of dual-fuel combustion to different SCR conversion efficiencies and fuel prices analysed.

\section{Experimental setup}

\subsection{Engine specifications and experimental facilities}

The experiments were performed on a single cylinder heavy-duty engine. Base hardware specifications are outlined in Table 1. The engine features a VVA system on the intake camshaft, incorporating a hydraulic tappet on the valve side of the rocker arm. The main intake valve 
opening (IVO) and closing (IVC) events were set at 365 and -152 CAD ATDC, respectively, as determined at $0.5 \mathrm{~mm}$ valve lift. The configuration provided an effective compression ratio of 16.1:1, which was calculated from the instantaneous in-cylinder volumes at IVC and TDC.

Table 1 - Single cylinder heavy-duty diesel engine specifications.

\begin{tabular}{ll}
\hline Parameter & Value \\
\hline Displaced Volume & $2026 \mathrm{~cm}^{3}$ \\
Stroke & $155 \mathrm{~mm}$ \\
Bore & $129 \mathrm{~mm}$ \\
Connecting Rod Length & $256 \mathrm{~mm}$ \\
Number of Valves & 4 \\
Piston Type & Re-entrant bowl \\
Geometric Compression & $16.8: 1$ \\
Ratio & \\
Diesel Injection System & Bosch common rail, \\
& injection pressure of 50-220 MPa, 8 \\
& holes with nominal diameter of 0.176 \\
& mm, included spray angle of $150^{\circ}$ \\
& PFI Marelli IWP069, included spray \\
Ethanol Injection System & angle of 15० \\
\hline
\end{tabular}

Figure 1 depicts a schematic diagram of the engine experimental setup. Fresh intake air was supplied to the engine via an external supercharger with closed loop for the boost pressure. A throttle located upstream of a large-volume surge tank provided fine control over the intake manifold air pressure. The air flow rate was measured with an Endress+Hauser Proline t-mass $65 \mathrm{~F}$ thermal mass flow meter. Another surge tank was installed in the exhaust manifold to damp out pressure fluctuations. An electronically controlled exhaust back pressure valve located downstream of the exhaust surge tank was used to set the required exhaust manifold pressure. High-pressure loop cooled external EGR was supplied to the engine via an EGR valve. Air and EGR temperatures were controlled using water cooled heat exchangers. Coolant and oil temperatures were set at $353 \mathrm{~K}$. Oil pressure was set at $0.45 \mathrm{MPa}$ throughout the experiments. 


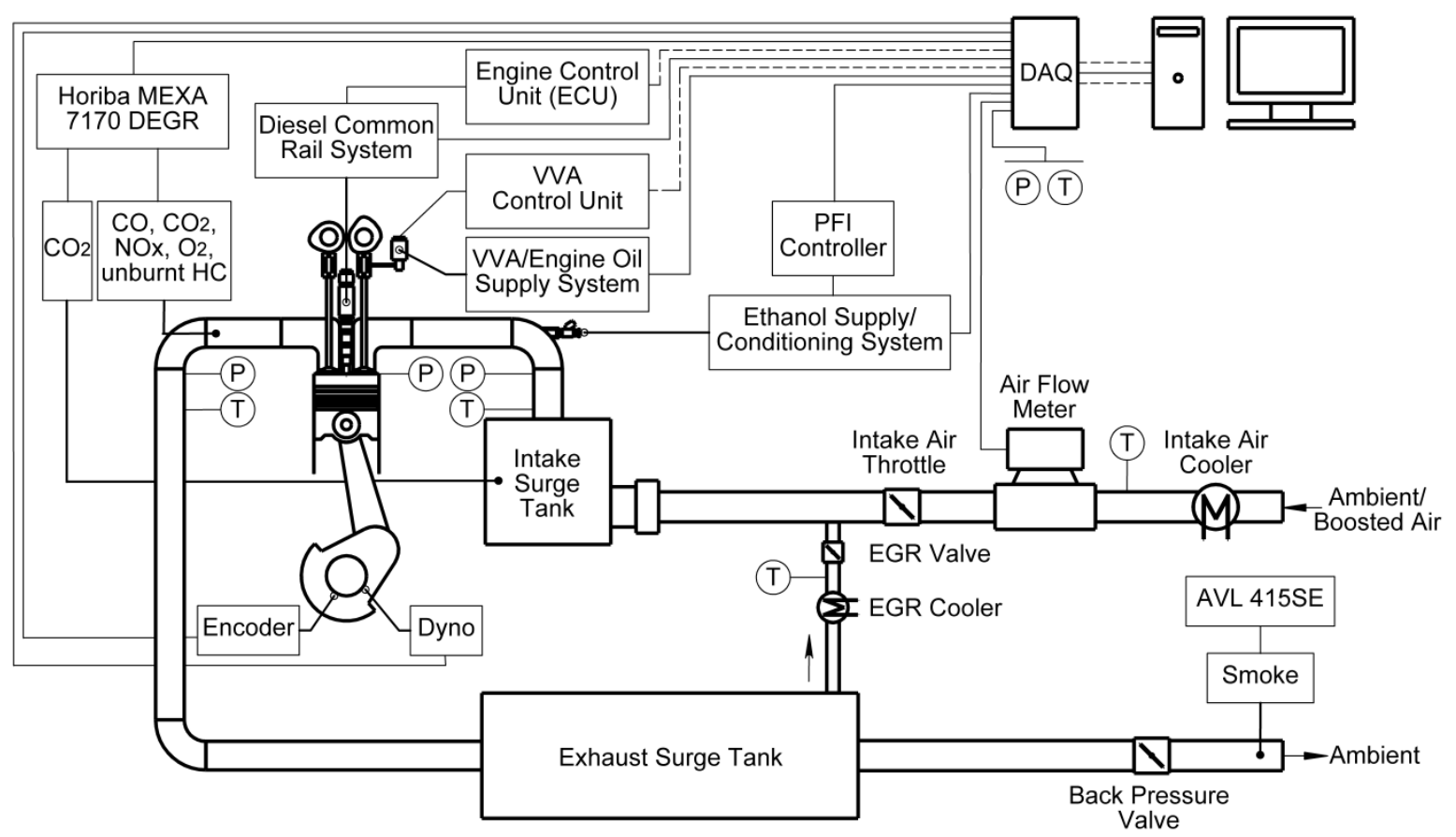

Figure 1 - Schematic diagram of the engine experimental setup.

\subsection{Fuel properties and delivery}

Fuel properties are shown in Table 2. During dual-fuel operation, ethanol was injected through a port fuel injector (PFI). An injector driver controlled the PFI pulse width, adjusted according to the desired ethanol energy fraction. The ethanol mass flow rate $\left(\dot{m}_{\text {ethanol }}\right)$ was obtained from an injector calibration curve determined with a semi-microbalance with an accuracy of $\pm 0.1 \mathrm{mg}$. Ethanol injection pressure was continuously monitored, so that a constant relative pressure of 0.3 $\mathrm{MPa}$ could be maintained across the injector. A heat exchanger held the ethanol temperature between $292 \mathrm{~K}$ and $298 \mathrm{~K}$.

The diesel fuel was supplied to the engine using a high pressure common rail injection system. The diesel injections were controlled via a dedicated engine control unit (ECU) with the ability to support up to three shots per cycle. Two Endress+Hauser Promass 83A Coriolis flow meters were used to measure the diesel flow rate $\left(\dot{m}_{\text {diesel }}\right)$ by considering the total fuel supplied to and from the high pressure pump and diesel injector. 
Table 2 - Fuel properties.

\begin{tabular}{lll}
\hline Property & $\begin{array}{l}\text { Gasoil Ultra Low } \\
\text { Sulphur }\end{array}$ & $\begin{array}{l}\text { Anhydrous } \\
\text { Ethanol }\end{array}$ \\
\hline Density at 293 K $(\rho)$ & $827 \mathrm{~kg} / \mathrm{m3}$ & $789 \mathrm{~kg} / \mathrm{m} 3$ \\
Cetane Number & $\sim 45$ & - \\
RON [28] & - & $\sim 107$ \\
Alcohol Content & - & $99.1-99.5 \%$ \\
Water Content & & $(\mathrm{v} / \mathrm{v})$ \\
Boiling Point/Range & $443-643 \mathrm{~K}$ & $<1.14 \%(\mathrm{w} / \mathrm{w})$ \\
Heat of Vaporisation $[28]$ & $270 \mathrm{~kJ} / \mathrm{kg}$ & $840 \mathrm{~kJ} / \mathrm{kg}$ \\
Carbon Content & $86.6 \%$ & $52.1 \%$ \\
Hydrogen Content & $13.2 \%$ & $13.1 \%$ \\
Oxygen Content & $0.2 \%$ & $34.8 \%$ \\
Lower Heating Value & $42.9 \mathrm{MJ} / \mathrm{kg}$ & $26.9 \mathrm{MJ} / \mathrm{kg}[28]$ \\
(LHV & & \\
\hline
\end{tabular}

The stoichiometric air/fuel ratio was determined by the conservation of mass of each chemical element in the reactants [28]. The global fuel/air equivalence ratio $\left(\Phi_{\text {global }}\right)$ was calculated using the intake air and fuel flow rates. The algorithm developed by Brettschneider-Spindt [29], which is based on the raw exhaust emissions, was used to confirm the results. The actual lower heating value of the fuels $\left(L H V_{D F}\right)$ in the dual-fuel mode was calculated as

$$
L H V_{D F}=\frac{\left(\dot{m}_{\text {ethanol }} L H V_{\text {ethanol }}\right)+\left(\dot{m}_{\text {diesel }} L H V_{\text {diesel }}\right)}{\left(\dot{m}_{\text {ethanol }}+\dot{m}_{\text {diesel }}\right)}
$$

The ethanol energy fraction (EF) varied from 0.0 to 0.8 during the experiments (or from $0 \%$ to $80 \%$ when expressed as a percentage) and was defined as

$$
E F=\frac{\dot{m}_{\text {ethanol }} L H V_{\text {ethanol }}}{\left(\dot{m}_{\text {ethanol }} L H V_{\text {ethanol }}\right)+\left(\dot{m}_{\text {diesel }} L H V_{\text {diesel }}\right)}
$$


2.3. Exhaust measurements

Gaseous emissions such as $\mathrm{CO}, \mathrm{CO}_{2}, \mathrm{NOx}$, and unburnt $\mathrm{HC}$ were taken using a Horiba MEXA7170 DEGR gas analyser system. The EGR rate was calculated by the ratio of intake and exhaust $\mathrm{CO}_{2}$ concentrations measured by the same analyser. The hydrocarbon emissions measured with its flame ionisation detector (FID) can lead to misinterpretation of the unburnt $\mathrm{HC}$ trends as a result of the relative insensitivity of the equipment towards alcohols and aldehydes [30]. Therefore, the FID response was corrected by the method developed in [31] to better account for the oxygenated unburnt organic species resultant from ethanol combustion. The calculation of the actual unburnt $\mathrm{HC}$ emissions used the raw $\mathrm{HC}$ measurements, a response factor of 0.68 for the hydrocarbon constituent [30], and the volumetric fraction of ethanol in the total fuel injected, as previously shown in [32]. Soot emissions were taken with an AVL 415SE smoke meter.

Combustion efficiency calculations were based on the emissions products not fully oxidised during the combustion process except soot by

$$
\text { Combustion Efficiency }=1-\frac{\left(I S C O L H V_{C O}\right)+\left(I S H C L H V_{D F}\right)}{\left(\dot{m}_{\text {ethanol }} L H V_{\text {ethanol }}\right)+\left(\dot{m}_{\text {diesel }} L H V_{\text {diesel }}\right)} P_{i}
$$

where ISCO and ISHC are the indicated specific emissions of $\mathrm{CO}$ and actual unburnt $\mathrm{HC}$, respectively; $L H V_{C O}$ is equivalent to $10.1 \mathrm{MJ} / \mathrm{kg}$; and $P_{i}$ is the net indicated power. The energy content of the unburnt hydrocarbons was assumed to have the lower heating value of the incylinder fuel mixture $L H V_{D F}$ calculated via Equation 1. 
2.4. Analysis of in-cylinder pressure signal and engine data

The in-cylinder pressure was measured using a Kistler 6125C piezoelectric pressure sensor working through an AVL FI Piezo charge amplifier. Intake and exhaust pressures were measured with two Kistler 4049A water cooled piezoresistive absolute pressure sensors. The intake valve lift profile was continuously monitored by a LORD Microstrain linear differential variable reluctance transducer located on the top of the valve spring retainer. Two National Instruments data acquisition (DAQ) cards were used to acquire the signals from the measurement device. A high speed DAQ card received the crank angle resolved data synchronised with an optical encoder of 0.25 CAD resolution. A lower speed DAQ card acquired the low frequency data, such as engine speed, torque, as well as temperatures and pressures at relevant locations. The data were calculated and displayed live by an in-house developed software.

Crank angle based in-cylinder pressure traces were averaged for 200 consecutive cycles for each operating point and used to calculate the IMEP and the apparent net heat release rate (HRR). Since the absolute value of the heat released is not as important to this study as the bulk shape of the curve with respect to crank angle, a constant ratio of specific heats $(\gamma)$ of 1.33 was assumed throughout the engine cycle. The mass fraction burnt (MFB) was calculated by integrating the HRR. Combustion phasing (CA50) was determined by the crank angle of $50 \%$ MFB.

The actual diesel injection timing was determined by post-processing the current signal sent from the ECU to the injector solenoid. This signal was taken using a current probe and corrected by adding the energising time delay of $0.345 \mathrm{~ms}$ (e.g. $\sim 2.5 \mathrm{CAD}$ at $1200 \mathrm{rpm}$ ) measured in a constant volume chamber. Ignition delay was defined as the period of time between the actual start of main injection (SOI_main) and start of combustion (SOC), set to $0.3 \%$ MFB point of the average cycle.

The PRR represents the mean value of the maximum pressure rise rates of two-hundred unfiltered in-cylinder pressure cycles. Unless specifically noted, the average in-cylinder pressure and 
the resulting HRR were post-processed using a third order Savitzky-Golay filter with a window size of five data points. Cycle-to-cycle variability was measured by the coefficient of variation of IMEP (COV_IMEP) over the sampled cycles. Pumping mean effective pressure (PMEP) was calculated by the subtraction of the gross from the net IMEP.

\section{Methodology}

Table 3 summarises the engine operating conditions for conventional diesel combustion baseline and ethanol-diesel dual-fuel combustion. The experiments were performed at a constant engine speed of $1200 \mathrm{rpm}$ and three loads of $0.9,1.2$, and $1.5 \mathrm{MPa}$ IMEP using $0 \%$ and $25 \%$ EGR. The ethanol energy fraction was increased from $0 \%$ to approximately $80 \%$. Diesel injection timings were swept near TDC (between -21 and 3 CAD ATDC) to identify the SOI_main that resulted in the maximum net indicated efficiency. The maximum in-cylinder pressure was limited to $18 \mathrm{MPa}$.

Stable engine operation was quantified by a COV_IMEP below 3\%.

Table 3 - Engine operating conditions at different loads.



A small pre-injection with an estimated volume of $3 \mathrm{~mm}^{3}$ and a constant dwell time of $1 \mathrm{~ms}$ between pre- and main injection events (SOl's) was used to reduce PRR's, which was limited to 2.0 MPa/CAD. This strategy employed the lowest amount of pre-injected diesel necessary to 
smooth the premixed combustion phase at the shortest dwell time for minimum deviation in the fuelling setpoint and compliance with hardware technical limitations. The estimation of the preinjected volume was obtained from an injector calibration map also determined using a constant volume chamber.

\section{Results and discussion}

The results and discussion section consists of seven individual parts. The first four are mainly focused on the effects of diesel pre-injection, ethanol energy fraction, EGR, and engine load on incylinder pressure and HRR profiles. The subsequent two sections provide a detailed discussion of the influence of the aforementioned parameters on combustion, emissions, and performance. Finally, exploration of a cost to benefit ratio is performed as well as an overall exhaust emissions analysis.

\subsection{The effect of diesel pre-injection}

Figure 2 shows the effect of diesel pre-injection on PRR and soot/NOx trade-off during an injection timing sweep in diesel-only mode. This initial study was performed with $25 \%$ EGR at the three engine loads of $0.9,1.2$, and 1.5 $\mathrm{MPa}$ IMEP. Rail pressures and injection characteristics are depicted in Table 3. The use of a pre-injection allowed for an extended operating range and lower PRR's while resulting in minimal impact on the soot/NOx trade-off compared against a single injection strategy. The levels of NOx emissions increased with earlier injection timings. This was due to the higher in-cylinder pressures and temperatures achieved under advanced combustion processes, which contributed to soot oxidation. 




Figure 2 - The effect of diesel pre-injection on PRR and soot/NOx trade-off of conventional diesel combustion with $25 \%$ EGR at different engine loads.

Figure 3 compares the effect of diesel pre-injection on reducing the rate of premixed combustion of both diesel-only (EF 0.0) and dual-fuel combustion (EF 0.8) modes at 1.2 MPa IMEP. Engine testing was carried out under similar conditions to Table 3, except for the use of an EGR rate of $20 \%$, a lower rail pressure of $110 \mathrm{MPa}$, and a constant SOI_main (non-optimised) for a given ethanol energy fraction. The average in-cylinder pressure traces were not filtered to highlight the importance of the pre-injection. The resulting HRR curves were post-processed as described in the methodology. 


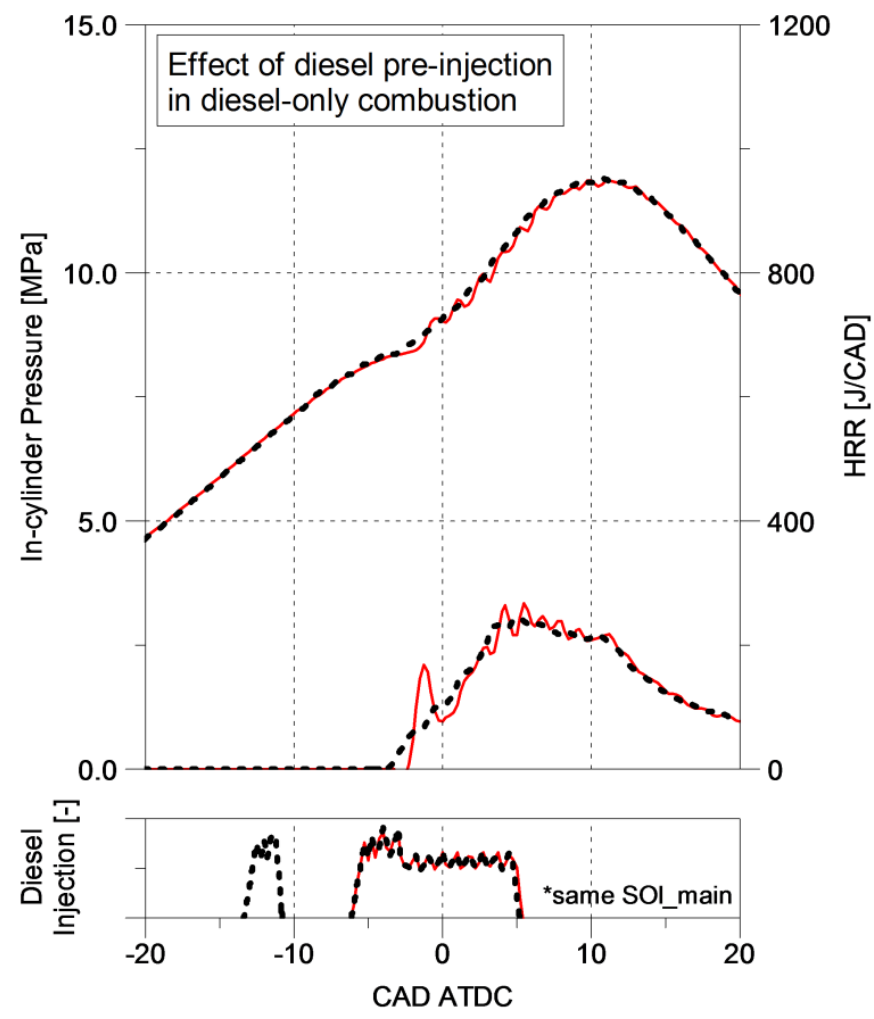

EF 0.0 | single inj.

.........EF 0.0 | pre + main

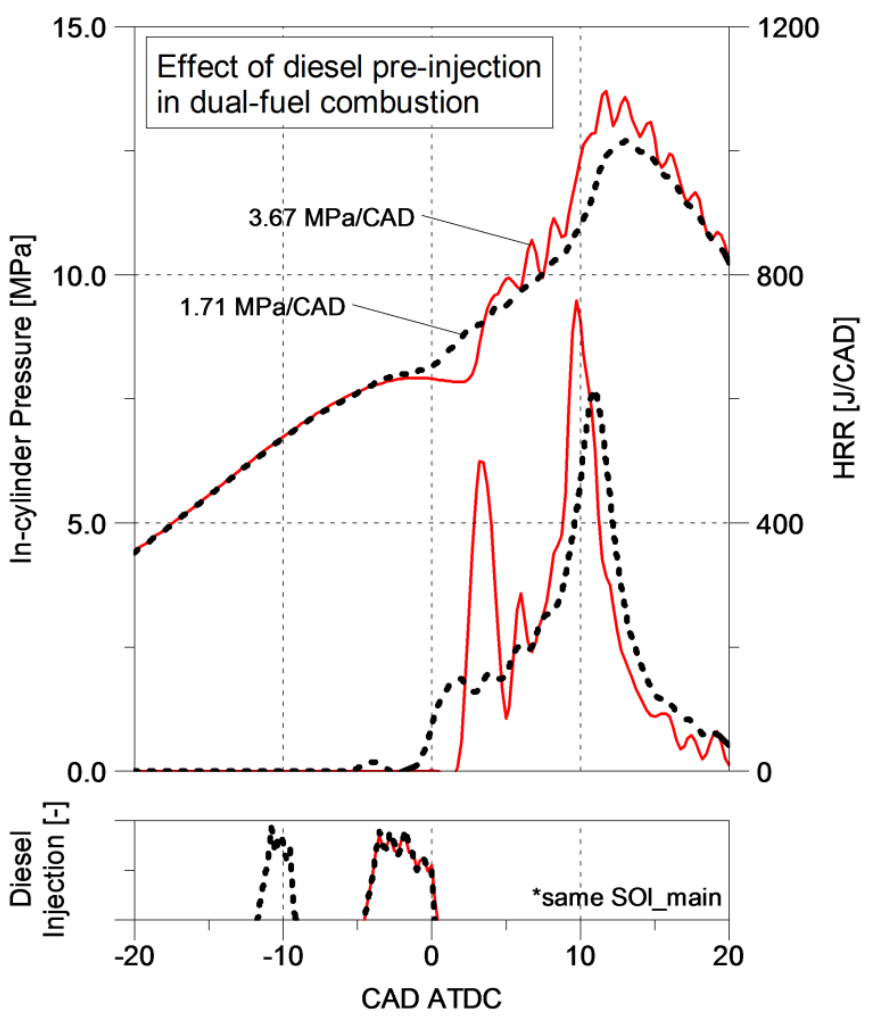

- EF 0.8 | single inj.

- EF 0.8 | pre + main

Figure 3 - The effect of diesel pre-injection on in-cylinder pressure and HRR of diesel-only (on the left) and dual-fuel combustion (on the right) at 1.2 MPa IMEP.

The ethanol-diesel dual-fuel combustion was characterised by higher PRR's and peak in-cylinder pressure than conventional diesel operation despite the use of slightly delayed diesel injection timing. In addition, the HRR has greater premixed combustion peaks in the dual-fuel mode, which suggests simultaneous combustion of diesel and entrained ethanol fuel [13]. The dual-fuel operation with a single injection strategy led to faster and more prominent premixed combustion, which accelerated the auto-ignition process of the remaining in-cylinder charge. The rapid burning resulted in ringing/knocking combustion with a PRR of $3.67 \mathrm{MPa} / \mathrm{CAD}$. The introduction of a small amount of diesel prior to the SOI_main reduced the maximum pressure rise rate to $1.71 \mathrm{MPa} / \mathrm{CAD}$ and caused minimal variations in the required energising time for the main diesel injection. Therefore, the use of a pre-injection of diesel was considered essential to explore the potential of ethanol-diesel dual-fuel combustion while complying with the PRR limit. 
4.2. The effect of ethanol energy fraction

Figure 4 depicts the effect of ethanol energy fraction on in-cylinder pressure and HRR using optimised diesel injection timings for the highest engine efficiency. For a constant load and EGR rate, the combustion process needed to be delayed as more ethanol was injected in order to avoid excessive PRR. The high heat of vaporisation of ethanol helped reduce the in-cylinder charge temperature and the subsequent compression pressures. Later combustion phasing lowered the peak in-cylinder pressures. The heat release profile changed from typical mixing controlled combustion in diesel-only mode to a shorter combustion process with higher heat release rates and some degree of premixed combustion.

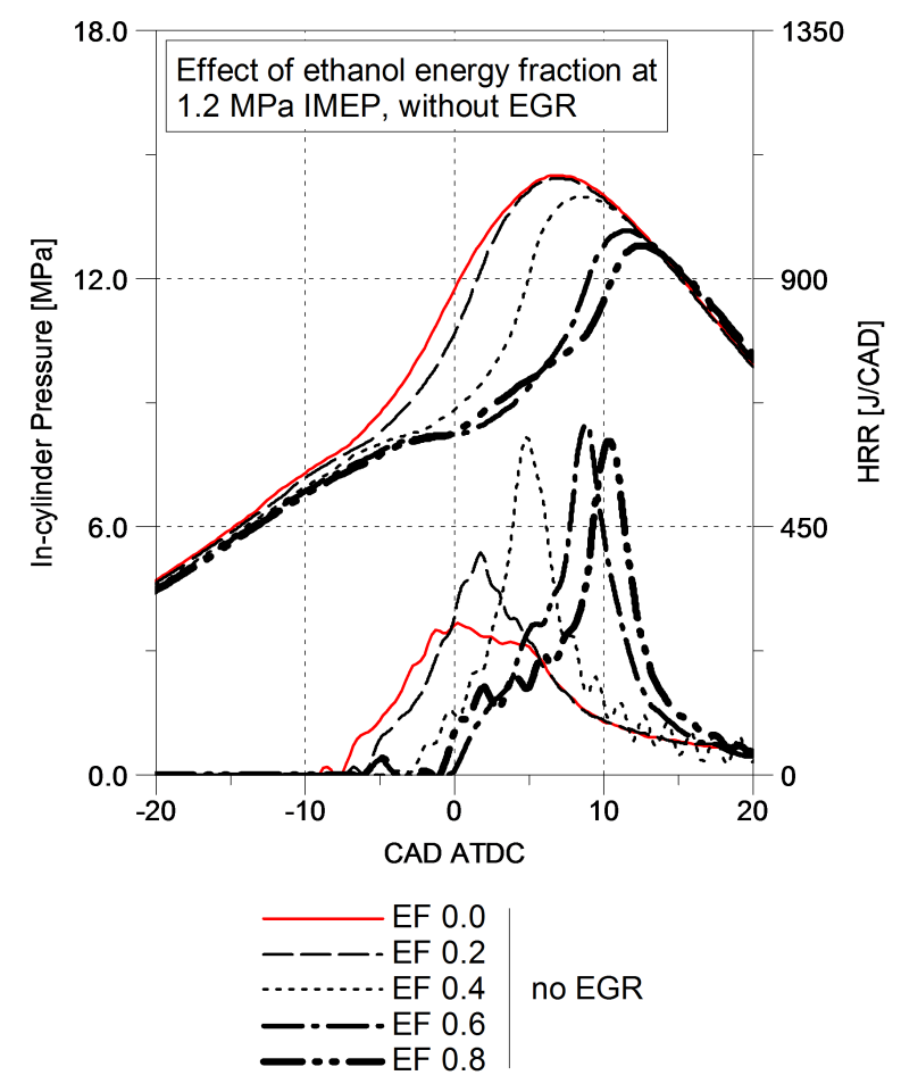

Figure 4 - In-cylinder pressure and HRR of the most efficient dual-fuel combustion cases using different ethanol energy fractions at 1.2 MPa IMEP. 


\subsection{The effect of EGR}

The use of EGR combined with an efficient SCR system can represent a cost-effective method for achieving emissions compliance and high engine efficiency $[3,26]$. To explore the trade-off between exhaust emissions and running costs, experiments focused on maximum indicated efficiency were performed with and without EGR. The introduction of a moderate EGR rate of $25 \%$ resulted in longer combustion durations and allowed for earlier combustion processes in most of the cases investigated, as depicted in Figure 5. This was attributed to reduced local combustion temperatures due to increased specific heat capacity of the in-cylinder charge (e.g. presence of $\mathrm{CO}_{2}$ in the recycled gases) and reduced oxygen availability (or dilution effect) [24,33].
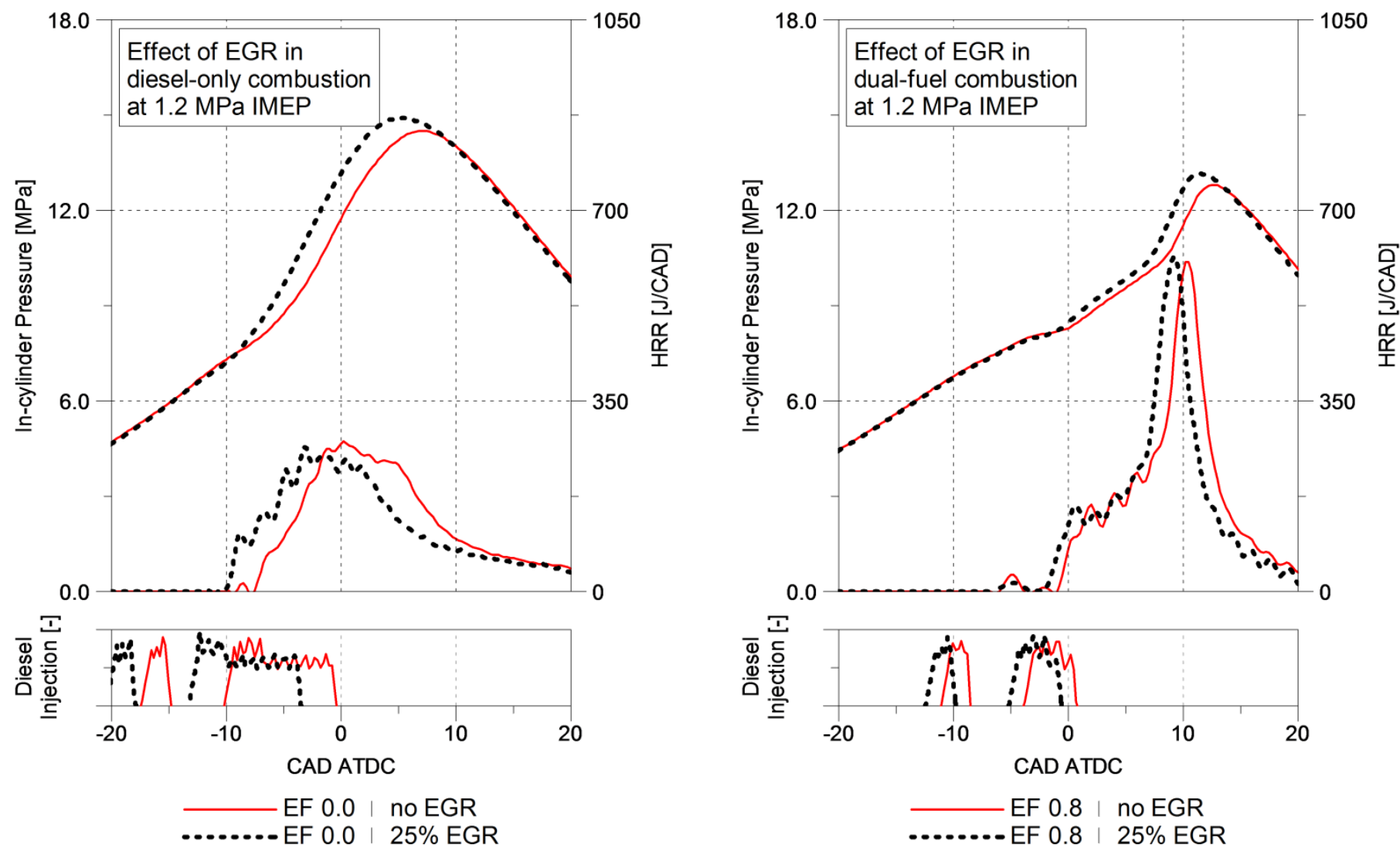

Figure 5 - The effect of EGR on in-cylinder pressure, HRR, and optimum diesel injection timings of diesel-only (on the left) and dual-fuel combustion (on the right). 


\subsection{The effect of engine load}

This section compares the effect of the engine load on conventional diesel combustion and dualfuel combustion with an ethanol energy fraction of $70 \%$. Figure 6 depicts the results attained without EGR. Ethanol-diesel dual-fuel operation required relatively later SOl's and delayed SOC as the load was increased in order to maintain PRR below the acceptable limit. The diesel fuel injected was responsible for initiating the combustion at the three engine loads. Higher compression pressures and temperatures as well as higher global fuel/air equivalence ratio accelerated the initiation of the auto-ignition process of the end gas at elevated loads, shortening the dual-fuel combustion duration.
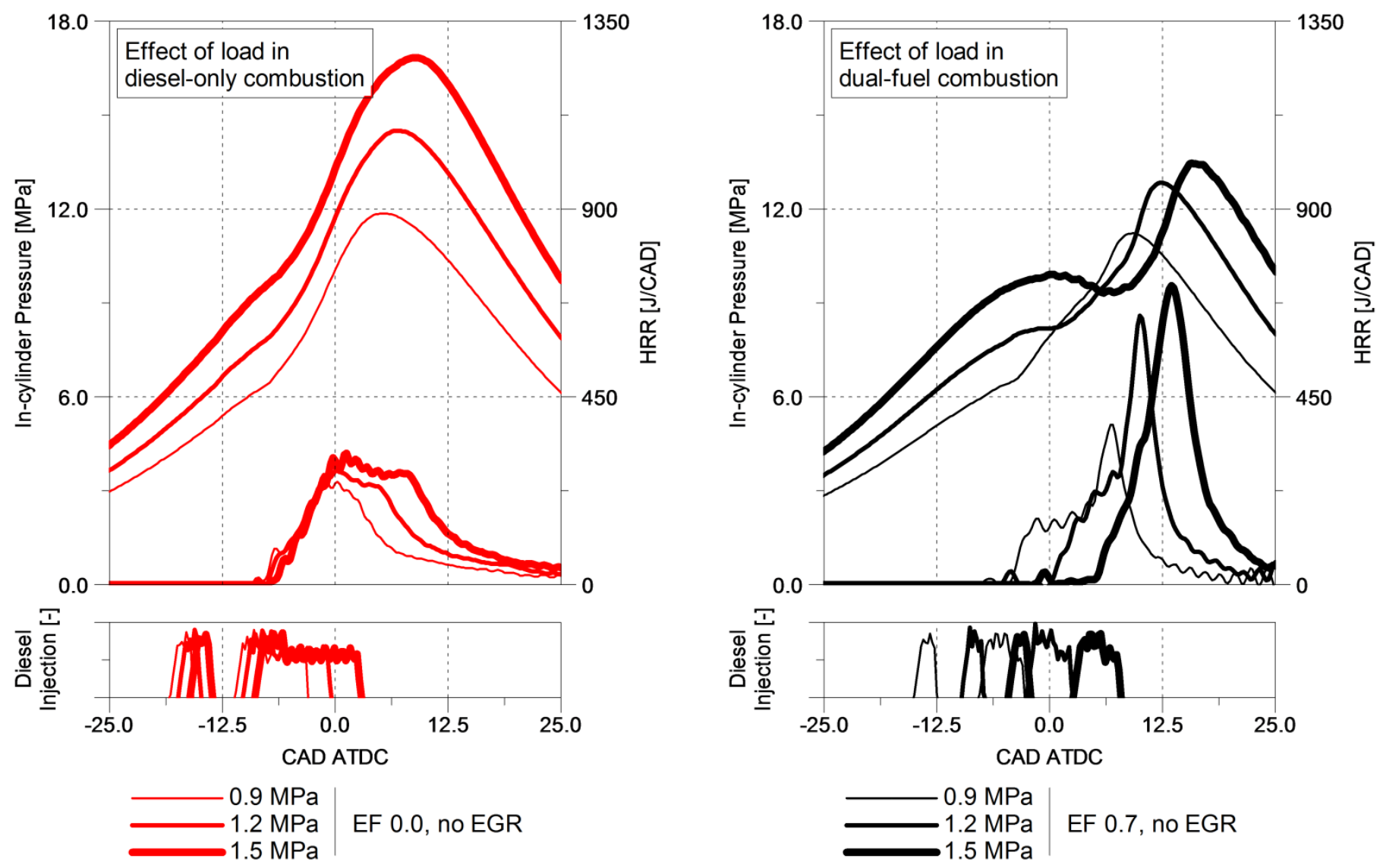

Figure 6 - The effect of engine load on in-cylinder pressure, HRR, and optimum diesel injection timings of diesel-only (on the left) and dual-fuel combustion (on the right). 
In contrast, the increase in load had little impact on the optimum injection timing, start of combustion (near -7.5 CAD ATDC), and end of combustion of the diesel-only mode. However, relatively more diesel fuel was burnt during the mixing-controlled combustion phase as the load was increased. This can be attributed to the shorter ignition delay, longer injection periods, and reduced amount of air/oxygen available, which limited the fuel vapour-air mixing process [28,34]. A similar trend was reported by Gao et al. [35] when characterising the conventional diesel combustion heat release at different loads using a constant intake oxygen concentration and fixed injection timing.

\subsection{Combustion characteristics}

Figure 7 shows the main diesel injection timings and the resulting heat release characteristics of ethanol-diesel dual-fuel combustion. Conventional diesel combustion was not PRR limited and allowed for the most advanced injection timings. The SOI_main was retarded as more ethanol was injected to maintain the maximum PRR below 2.0 MPa/CAD. The dual-fuel operation with constant injection timing would result in excessive PRR's for early start of injections and inefficient combustion processes for late ones. The injection timing trend was reversed when running the engine with an ethanol energy fraction of $60-70 \%$. Relatively earlier injections were required as the amount of ethanol was increased towards $76-80 \%$ due to low reactivity of the in-cylinder charge (e.g. reduced amount of diesel). 

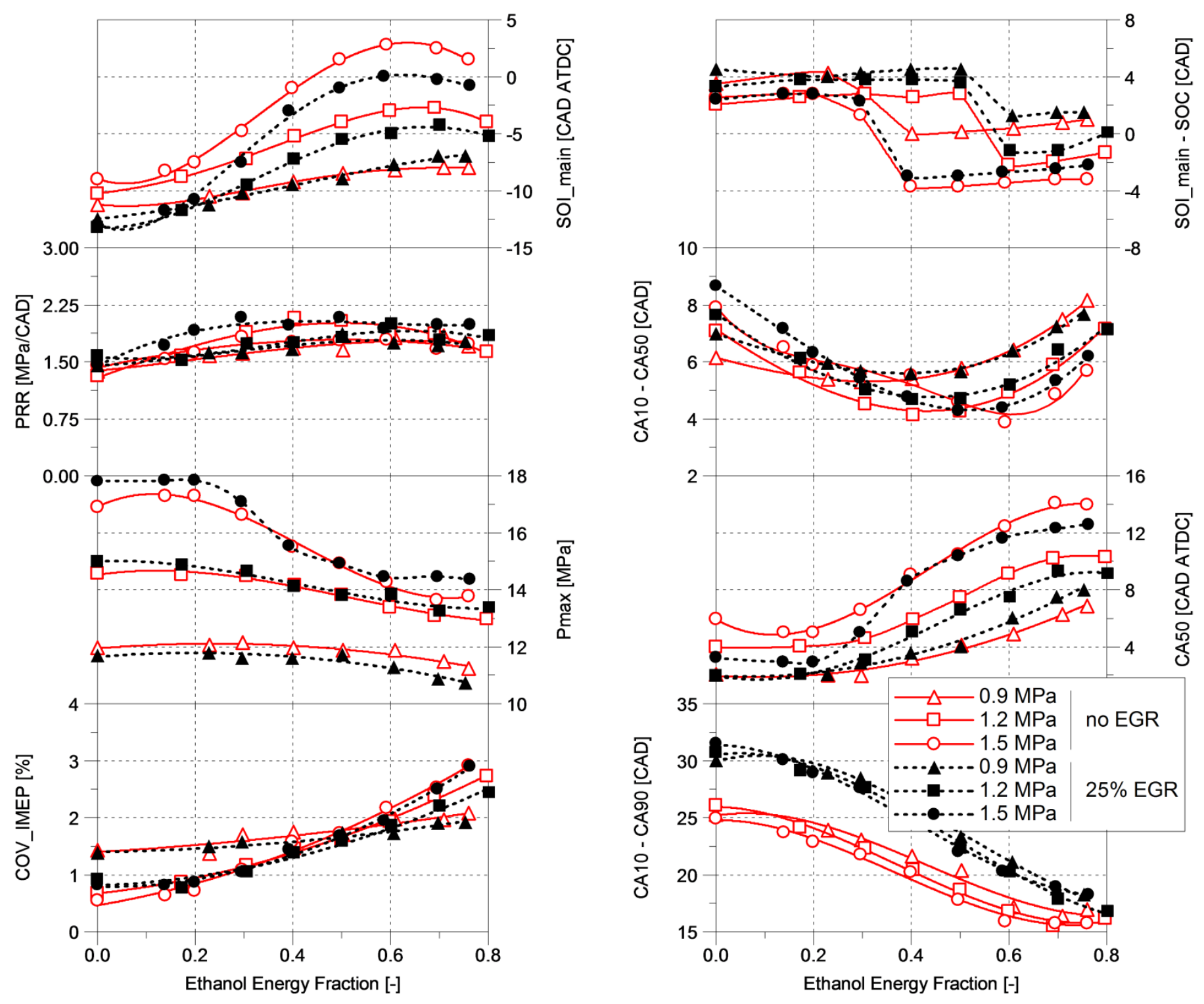

Figure 7 - Main diesel injection timings and the resulting heat release characteristics.

Adding 25\% EGR generally allowed for advanced diesel injections due to longer burn durations and possibly lower local combustion temperatures. The use of a constant SOI with a higher EGR rate would likely lead to later combustion events [8]. The increase of the engine load yielded the opposite effects, limiting the maximum advance. The optimum injection timings with and without EGR were somewhat similar at $0.9 \mathrm{MPa}$ IMEP as the combustion was more sensitive to the higher intake charge temperature introduced by the recycled gases.

Maximum in-cylinder pressure (Pmax) increased with load as a result of greater boost pressures and quantity of fuel injected/energy released. Pmax was reduced by the use of higher ethanol 
fractions mainly due to later combustion events. The limitation of peak pressure started to become an issue only when running with EGR and low ethanol percentages at the highest load of $1.5 \mathrm{MPa}$ IMEP. The introduction of EGR typically allowed for earlier combustion phasing, leading to higher Pmax. The exception occurred at the lightest load of $0.9 \mathrm{MPa}$ IMEP, where the use of EGR increased the premixed combustion peak and limited the maximum injection timing advance. Consequently, Pmax with EGR dropped in comparison with the cases without EGR. This was a result of relatively lower in-cylinder charge dilution (e.g. higher intake oxygen/nitrogen concentration) [24] and an increase of $9 \mathrm{~K}$ in the intake charge temperature.

COV_IMEP rose when the ethanol energy fraction was increased. This trend was attributed to the lower reactivity of the ethanol fuel and its dependency on the temperature rise introduced by the diesel fuel to initiate combustion. To some extent, higher engine loads and the use of EGR reduced the COV_IMEP due to increased fuel/air equivalence ratio. However, combustion instability with ethanol fractions above $60 \%$ was higher at 1.2 and $1.5 \mathrm{MPa}$ IMEP than at $0.9 \mathrm{MPa}$ IMEP. This is likely a result of the cyclic variability introduced by the auto-ignition process of ethanol and is supported by a slight increase in the coefficient of variation of Pmax (not shown for brevity).

The analysis of the heat released showed that the ignition delay between the start of pre-injection (SOI_pre) and SOC was always positive, which means combustion was controlled by the diesel injections. However, there were cases with negative ignition delay between SOI_main and SOC (on top right of Figure 7), which indicated the combustion was starting prior to the main diesel injection timing. The shorter ignition delay was possibly a result of the higher fuel-air equivalence ratios obtained when the ethanol fraction and engine load were increased. Alternatively, the introduction of EGR led to slightly longer ignition delays. This was attributed to the higher heat capacity and dilution effect of the EGR that slowed down the onset of ignition and hampered the mixing between oxygen and fuel [33]. 
After the ignition occurred, the first part of the heat release process between CA10-CA50 became shorter as the ethanol percentage was increased. The ethanol fuel progressively burnt as the diffusion combustion took place. However, there was a reversal of the trend between the ethanol energy fractions of $40 \%$ and $60 \%$, depending on the engine load. For the conditions with higher levels of premixed ethanol, it is likely the fuel slowed the reaction rates due to its cooling effect and low reactivity. Despite the relatively longer CA10-CA50 period measured, it was still necessary to maintain or delay CA50 to avoid high PRR. The resulting CA50's depicted similar response to changes in diesel injection timings.

Higher ethanol fractions and elevated engine loads resulted in faster CA10-CA90. The greatest reduction in combustion duration occurred when using EGR at 1.2 MPa IMEP, where the CA10CA90 was shortened from 30.7 CAD in diesel-only mode to 16.7 CAD in the dual-fuel combustion with an ethanol percentage of $80 \%$. The use of EGR was effective in slowing down the combustion process, increasing the CA10-CA90 by up to $29 \%$.

\subsection{Exhaust emissions and performance}

Figure 8 depicts indicated specific emissions, global fuel/air equivalence ratio, and efficiencies of ethanol-diesel dual-fuel combustion. NOx emissions were reduced by $39-68 \%$ at the highest ethanol energy fractions. More homogeneous combustion with high ethanol percentages possibly helped minimise NOx production at the outer boundary of the diesel diffusion flame. Later combustion phasing and lower Pmax also contributed to this improvement. 

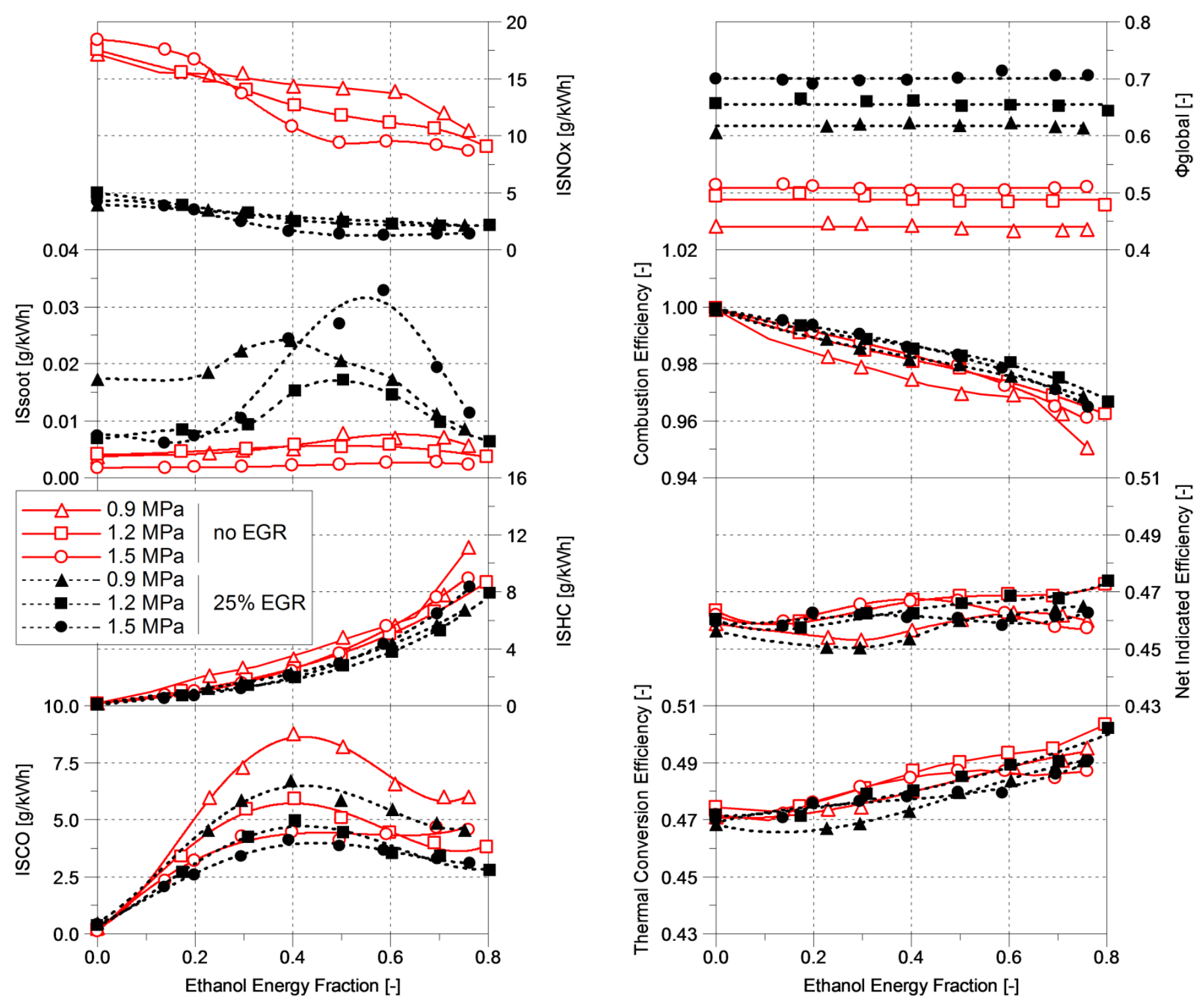

Figure 8 - Exhaust emissions and performance.

In one specific case at $0.9 \mathrm{MPa}$ IMEP, ISNOx levels without EGR were decreased from 17.1 $\mathrm{g} / \mathrm{kWh}$ in conventional diesel combustion to $10.4 \mathrm{~g} / \mathrm{kWh}$ in the dual-fuel mode with $76 \%$ ethanol. The use of EGR and the increase of the engine load to 1.5 MPa IMEP allowed for further NOx reductions due to relatively lower oxygen availability [28]. On average, the introduction of the EGR dropped the NOx emissions by $80 \%$ while maintaining a similar trend to that of the cases where no EGR was used. This can be demonstrated by the decrease from 10.4 to $2.1 \mathrm{~g} / \mathrm{kWh}$ when operating the engine with an ethanol fraction of $76 \%$ at $0.9 \mathrm{MPa}$ IMEP. 
The smoke number was maintained under 0.1 FSN without EGR, which was equivalent to an ISsoot below $0.008 \mathrm{~g} / \mathrm{kWh}$, independent of ethanol percentage and load. Soot emissions slightly increased with the ethanol energy fraction due to later combustion processes and lower local incylinder temperatures. To some extent, lighter loads tend to produce more soot emissions than higher loads as a result of lower rail pressures and reduced end-of-combustion temperatures [36].

The presence of EGR elevated levels of ISsoot due to reduced oxygen concentration and lower combustion temperatures. Ethanol fractions between approximately $40 \%$ and $60 \%$ resulted in an apparent "soot bump" associated with a rapid CA10-CA50 duration and thus shorter mixing time prior to the auto-ignition of ethanol. As the port fuel injected ethanol fraction increased towards 76$80 \%$, combustion became more homogenous and less diesel fuel was available for soot formation. As a result, the dual-fuel combustion with 25\% EGR attained smoke levels between 0.006-0.011 $\mathrm{g} / \mathrm{kWh}$.

Conventional diesel combustion yielded values under $0.5 \mathrm{~g} / \mathrm{kWh}$ and $0.2 \mathrm{~g} / \mathrm{kWh}$ for ISCO and ISHC, respectively, maintaining high combustion efficiencies throughout the sweep of load and EGR. In comparison, the port fuel injection of a low reactivity fuel usually leads to higher levels of late cycle $\mathrm{CO}$ and unburnt $\mathrm{HC}$. This effect was shown by computational fluid dynamics modelling performed by Kokjohn et al. [19] and Desantes et al. [22], where it was revealed that fuel is trapped in the crevice and squish volumes of a stock diesel combustion system. Therefore, it would be generally accepted that the use of higher ethanol energy fractions would lead to increased unburnt $\mathrm{HC}$ emissions.

For the specific cases investigated in this study, engine load had little influence on unburnt hydrocarbon emissions for a constant ethanol percentage. The ISHC was slightly reduced at 1.2 MPa IMEP when compared to the levels measured at $0.9 \mathrm{MPa}$ IMEP due to a higher $\Phi_{\text {global. }}$. However, ISHC increased at 1.5 MPa IMEP mostly as a result of later combustion processes and lower local in-cylinder gas temperatures. The introduction of EGR was beneficial to ISHC 
reduction because of the relatively higher fuel/air equivalence ratio of the premixed charge. ISHC was more susceptible to the low $\Phi_{\text {global }}$ obtained without EGR at $0.9 \mathrm{MPa}$ IMEP.

The ISCO exhibited a different trend from ISHC. Carbon monoxide emissions increased rapidly as more diesel fuel was substituted with ethanol until it reached a peak at ethanol energy fractions of approximately $40 \%$. These conditions represent dual-fuel combustion processes with some of the shortest CA10-CA50 periods. The results are indicative of inappropriate mixing time and show a transition between stratified dual-fuel combustion and ethanol-dominated heat release [25].

CO emissions decreased as the ethanol fraction was increased from $40 \%$ towards $80 \%$, which is likely linked to the reduction in partial oxidation of the premixed fuel. Relatively lower levels of ISCO at high ethanol percentages was also reported by Han et al. [10] over a sweep of intake oxygen concentration at 1.0 MPa IMEP. Higher engine loads and the use of EGR were effective in reducing $\mathrm{CO}$ emissions, mainly due to increased global fuel/air equivalence ratio.

Since combustion efficiency is determined by $\mathrm{CO}$ and unburnt $\mathrm{HC}$ emissions, its level gradually decreased with higher ethanol energy fractions and reached approximately $96 \%$ at the maximum substitution ratios. At the lightest load of $0.9 \mathrm{MPa}$, the dual-fuel operation without EGR led to lowest combustion efficiency of $95 \%$ as a result of reduced in-cylinder gas temperatures and $\Phi_{\text {global. }}$

Net indicated efficiency is a dimensionless parameter that relates the indicated power to the amount of fuel energy delivered. Net indicated efficiency varied slightly with ethanol content and EGR at the three mid-loads investigated. This shows the efficiency was found to be affected by the combustion efficiency and heat transfer, as the pumping losses were kept approximately the same at a given load. The best dual-fuel results were achieved at 1.2 MPa IMEP, where net indicated efficiency reached more than $47 \%$ using an ethanol energy fraction of $80 \%$. Peak in-cylinder pressure and PRR limitations combined with a high $\Phi_{\text {global }}$ (e.g. heat transfer loss) constrained 
improvements in engine performance at 1.5 MPa IMEP compared to the medium load of $1.2 \mathrm{MPa}$ IMEP.

At 0.9 MPa IMEP, the overly lean in-cylinder charge somewhat degraded the efficiencies at low ethanol percentages of $20-40 \%$. As the ethanol fraction was increased, net indicated efficiency was recovered by reduced heat transfer loss due to shorter combustion duration and lower peak in-cylinder pressures. Higher intake charge temperature and relatively longer ignition delay introduced by the use of EGR increased the premixed combustion peak and limited advanced combustion events at 0.9 MPa IMEP. As a result, net indicated efficiency was slightly reduced with $25 \%$ EGR.

The thermal conversion efficiency was calculated to evaluate the maximum theoretical thermodynamic efficiency of the engine by subtracting the effects of combustion efficiency and pumping losses from the net indicated efficiency. The analysis showed that the port fuel injection of ethanol in a heavy-duty diesel engine can lead to thermal conversion efficiencies of more than $50 \%$ with an ethanol energy fraction of $80 \%$ at the load of $1.2 \mathrm{MPa}$ IMEP. This is likely attributed to a reduction in heat transfer losses introduced by lower local in-cylinder gas temperatures and optimum start- and end-of-combustion timings.

Improvements in thermal conversion efficiency with EGR were often counterbalanced by a higher global fuel/air equivalence ratio and longer combustion duration, despite the lower peak combustion temperatures. Therefore, ethanol-diesel dual-fuel combustion has the potential to simultaneously yield high thermal conversion efficiencies and low NOx emissions. The effectiveness of the alternative combustion strategy in terms of operational cost is discussed in the next section.

\subsection{Cost-benefit and overall emissions analysis}


The practical use of ethanol in a heavy-duty diesel engine is linked to several aspects, such as fuel prices, volumetric fuel consumption, engine performance, and exhaust emissions. Therefore, a cost-benefit and overall emissions analysis was carried out to determine the best way to utilise ethanol as a fuel.

Figure 9 shows the total fuel energy flow rate and the relative volumetric fuel flow rate at different engine operating conditions. The fuel energy consumption rose with load and remained practically constant when more ethanol and/or EGR were used. However, the ratio of the total volumetric fuel flow rate to the diesel flow rate in the baseline diesel-only cases increased with the ethanol energy fraction. The dual-fuel combustion with ethanol percentages of $76-80 \%$ resulted in approximately $50 \%$ higher volumetric fuel consumption (e.g. $\mathrm{dm}^{3} / \mathrm{h}$ ) than conventional diesel combustion. The increase in total volumetric fuel flow rate is attributed to the differences in fuel densities and LHV (see Table 2).

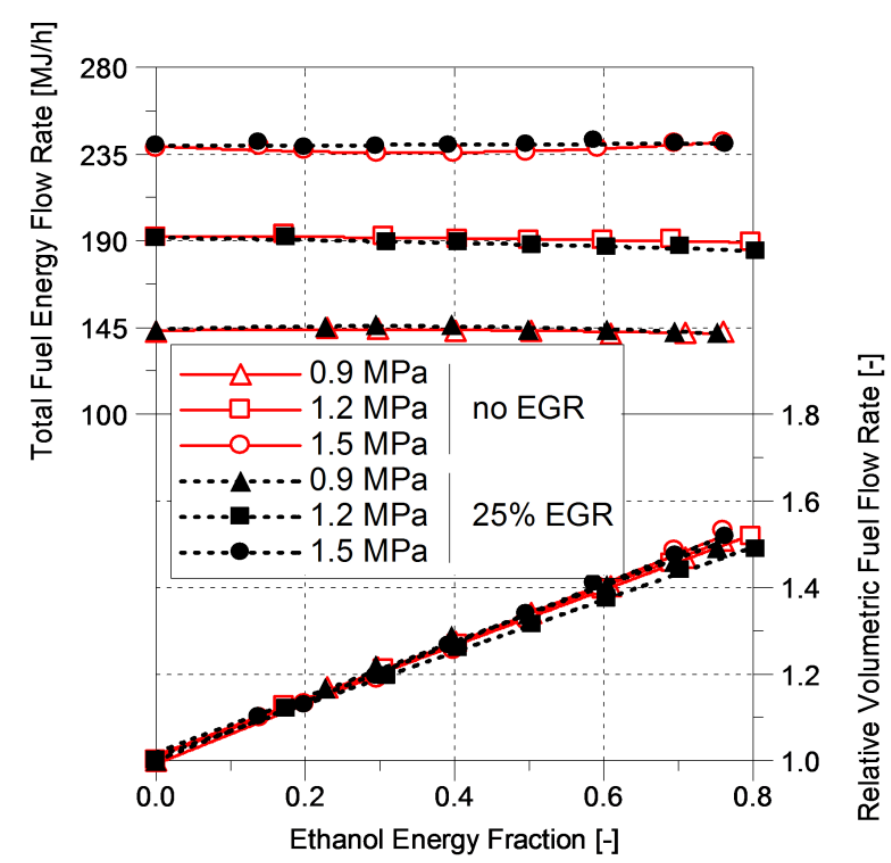

Figure 9 - Total fuel energy flow rate and relative volumetric fuel flow rate.

The fuel properties can be used to obtain an economic assessment of the maximum volumetric price ratio $\left(V P R_{\max }\right)$ between ethanol and diesel fuels, as shown in Equation 4 . If one considers the fuel energy flow rate has been kept constant as more ethanol was injected at a given operating 
condition, dual-fuel combustion will be cost-effective when the relative price of one litre of



$$
V P R_{\text {max }}=\left(\frac{\text { Price }_{\text {ethanol }}}{\text { Price }_{\text {diesel }}}\right)_{\text {max }}=\frac{\rho_{\text {ethanol }} L H V_{\text {ethanol }}}{\rho_{\text {diesel }} L H V_{\text {diesel }}} \approx 60 \%
$$

In addition to fuel prices, the total cost of ownership will be affected by the operating cost of the aftertreatment system. The Euro VI emissions regulation applied for heavy-duty vehicles [37] limits the NOx and the particulate matter emissions to $0.4 \mathrm{~g} / \mathrm{kWh}$ and $0.010 \mathrm{~g} / \mathrm{kWh}$, respectively. The regulation also sets maximum levels of $\mathrm{CO}$ and unburnt $\mathrm{HC}$ emissions equivalent to $1.5 \mathrm{~g} / \mathrm{kWh}$ and $0.13 \mathrm{~g} / \mathrm{kWh}$, respectively.

The emissions standard limits were not fully met by the in-cylinder measures investigated in this work. However, low levels of soot emissions were attained and can be further reduced with higher diesel injection pressures. Alternatively, smoke control can be achieved using diesel particulate filters typically required in heavy-duty diesel applications. Despite of this, the use of this aftertreatment system is associated with higher backpressure and involves periodic regenerations, resulting in fuel economy penalty [5-7]. Although the majority of the $\mathrm{CO}$ and unburnt $\mathrm{HC}$ emissions produced by dual-fuel combustion can be removed by a diesel oxidation catalyst [38], extremely high $\mathrm{HC}$ conversion efficiencies will be necessary to comply with the stringent tailpipe unburnt $\mathrm{HC}$ emissions of $0.13 \mathrm{~g} / \mathrm{kWh}$.

NOx emissions still present a challenge depending on the engine calibration due to limited conversion efficiency of the SCR system and/or high aqueous urea solution usage (e.g. increased engine operational cost). The NOx conversion (Conv.Eff) of practical SCR aftertreatment systems typically ranges between $80 \%$ and $90 \%$ [34,39]. Higher conversion of $97 \%$ is likely 
attained with optimised closed loop control of aqueous urea solution injection [6] or with the introduction of an additional flow-through SCR catalyst [40].

Figure 10 compares the estimated SCR-out NOx levels attained with different SCR conversion efficiencies when operating the engine with and without EGR at 1.2 MPa IMEP. The shaded areas represent the sensitivity of NOx emissions when the conversion efficiency was varied from $80 \%$ to 97\%. The lines in between indicate the NOx emissions for an SCR system with $90 \%$ removal efficiency. The levels of ISNOx downstream of the SCR system were calculated as

$$
\text { SCR - out ISNOx }=\left(\frac{100-\text { Conv.Eff }}{100}\right) \text { ISNOx }
$$

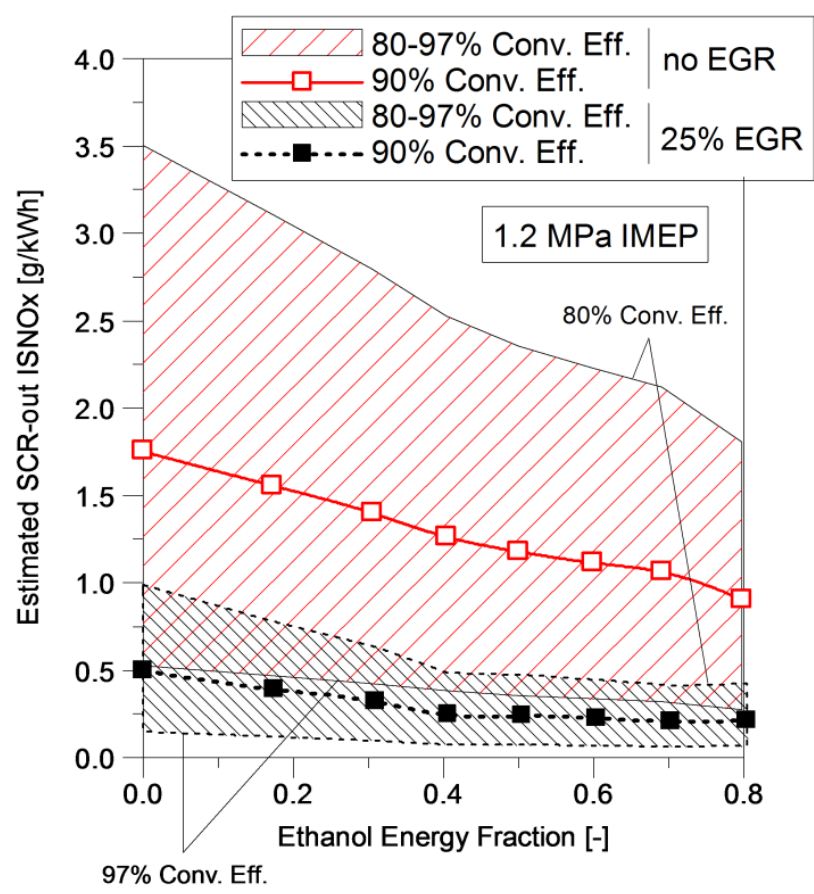

Figure 10 - Estimated ISNOx levels for different SCR conversion efficiencies.

The use of low ethanol fractions of $0-30 \%$ without EGR resulted in estimated SCR-out ISNOx higher than the Euro VI standard limit of $0.4 \mathrm{~g} / \mathrm{kWh}$, independent of the NOx removal efficiency. Later diesel injection timings are likely to be required at these particular conditions, which would adversely affect soot emissions and indicated efficiency. Alternatively, the use of $25 \%$ EGR 
allowed for NOx emissions compliance when running with ethanol percentages above $20 \%$ and an SCR conversion efficiency of $90 \%$. The combination of a high ethanol energy fraction of $80 \%$ and EGR led to an ISNOx reduction of $88 \%$ compared with conventional diesel combustion without EGR at a given SCR efficiency.

A decrease in ISNOx levels allows for operational cost savings as a result of lower aqueous urea solution consumption $\left(\dot{m}_{\text {urea }}\right)$ in the SCR system. To determine the effectiveness of the use of ethanol and EGR in terms of running costs, the $\dot{m}_{\text {urea }}$ required to reduce the ISNOx levels to the Euro VI emissions standard limit was calculated as

$$
\dot{m}_{\text {urea }}=0.01\left(I S N O x-I_{\text {ISNOX }} \text { Euro VI }_{l}\right)\left(\dot{m}_{\text {diesel }}+\dot{m}_{\text {ethanol }} \frac{L H V_{\text {ethanol }}}{L H V_{\text {diesel }}}\right)
$$

where $\dot{m}_{\text {urea }}$ is estimated at $1 \%$ of the diesel equivalent fuel flow rate per $\mathrm{g} / \mathrm{kWh}$ reduction in NOx emissions $[4-6,26,41]$. Adding the estimated $\dot{m}_{\text {urea }}$ to the measured diesel fuel flow rate allowed for the calculation of the SCR corrected net indicated efficiency (Net Indicated Eff $\cdot$ SCR corr.), which was defined as

$$
\text { Net Indicated Eff } \cdot \text { SCR corr. }=\frac{P_{i}}{\left(\dot{m}_{\text {diesel }}+\dot{m}_{\text {urea }}\right) L H V_{\text {diesel }}+\left(\dot{m}_{\text {ethanol }}\right) L H V_{\text {ethanol }}}
$$

The aqueous urea solution was simulated to have the same cost and "properties" of the diesel fuel [26], as their relative prices vary according to region and purchase order quantity [6]. The estimated $\dot{m}_{\text {urea }}$ to meet the Euro $\mathrm{VI}$ heavy-duty NOx emissions target and resulting Net Indicated Eff.SCR corr. are shown in Figure 11. 


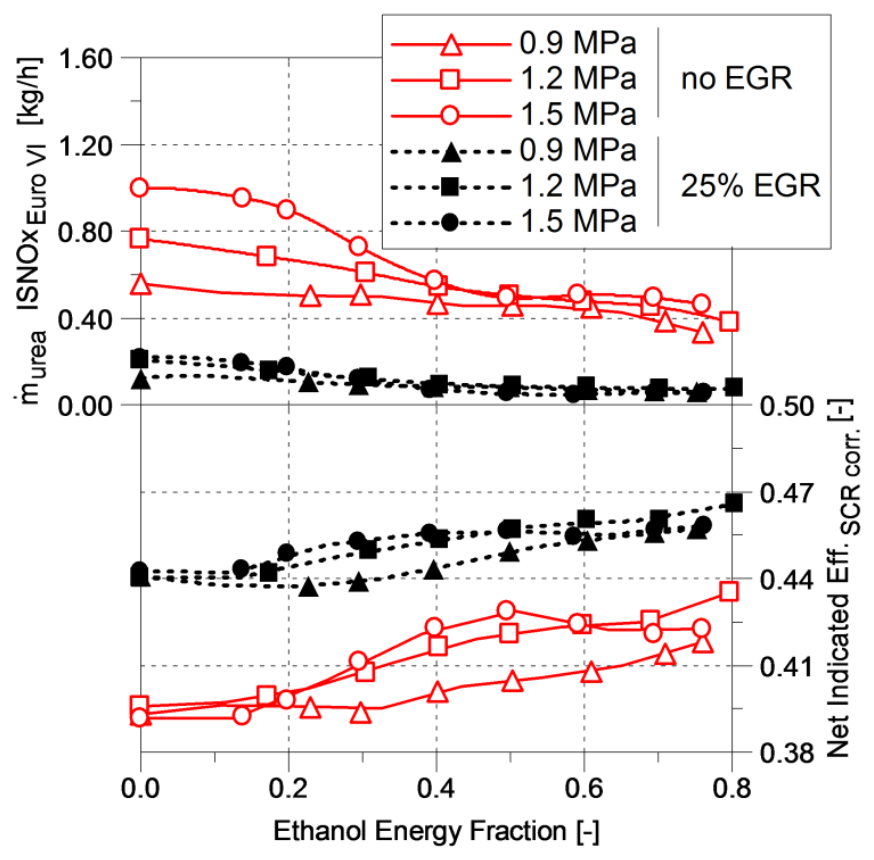

Figure 11 - Estimated aqueous urea solution flow rate to meet the Euro VI heavy-duty NOx emissions target and SCR corrected net indicated efficiency.

Conventional diesel combustion and no EGR operation resulted in lower SCR corrected net indicated efficiency due to higher urea consumption. The use of ethanol and EGR minimised the NOx emissions and thus the $\dot{m}_{\text {urea }}$ required. This allowed for higher Net Indicated Eff.sCR corr., effectively translating into lower running costs.

If the fuel prices (e.g. per litre) are known, the engine operational cost ratio (EOCR) can be calculated as

$$
E O C R=\left(\frac{\frac{\text { Price }_{\text {ethanol }}}{\rho_{\text {ethanol }} L H V_{\text {ethanol }}}(E F)+\frac{\text { Price }_{\text {diesel }}}{\rho_{\text {diesel }} L H V_{\text {diesel }}}(1-E F)}{\frac{\text { Price }_{\text {diesel }}}{\rho_{\text {diesel }} L H V_{\text {diesel }}}}\right)\left(\frac{\text { Net Indicated } E f f \cdot \text { baseline }}{\text { Net Indicated Eff } \cdot \text { SCR corr. }}\right)-1
$$

which includes the consumption of aqueous urea solution via Net Indicated $E f f \cdot{ }_{\text {SCR }}$ corr. The result of this equation will characterise an increase or decrease in running costs compared to a baseline engine operation without an SCR aftertreatment system $\left(\dot{m}_{\text {urea }}=0\right)$. This condition was 
represented by the net indicated efficiencies of the conventional diesel combustion cases with and without EGR (Net Indicated $E f f \cdot$ baseline $)$ showed in Figure 8 . The use of the $V P R_{\text {max }}$ in Equation 8 simplifies the formula as

$$
E O C R=\left(\frac{V P R}{V P R_{\max }}(E F)+(1-E F)\right)\left(\frac{\text { Net Indicated } E f f \cdot \text { baseline }}{\text { Net Indicated } E f f \cdot S C R \text { corr. }}\right)-1
$$

where $V P R$ is the actual volumetric price ratio between ethanol and diesel fuels. Therefore, the $E O C R$ will rely exclusively on the engine efficiency ratio when $V P R=V P R_{\max } \approx 60 \%$.

Figure 12 shows the influence of the $V P R$ on the engine operational cost ratio at $1.2 \mathrm{MPa}$ IMEP. Lower EOCR represents a reduced cost of ownership. The symbols indicate the sensitivity of the EOCR to a $V P R$ of $60 \%$ as the ethanol energy fraction was varied with and without EGR. The shaded areas depict the estimated EOCR when the volumetric price ratio varies from $50 \%$ to $70 \%$.

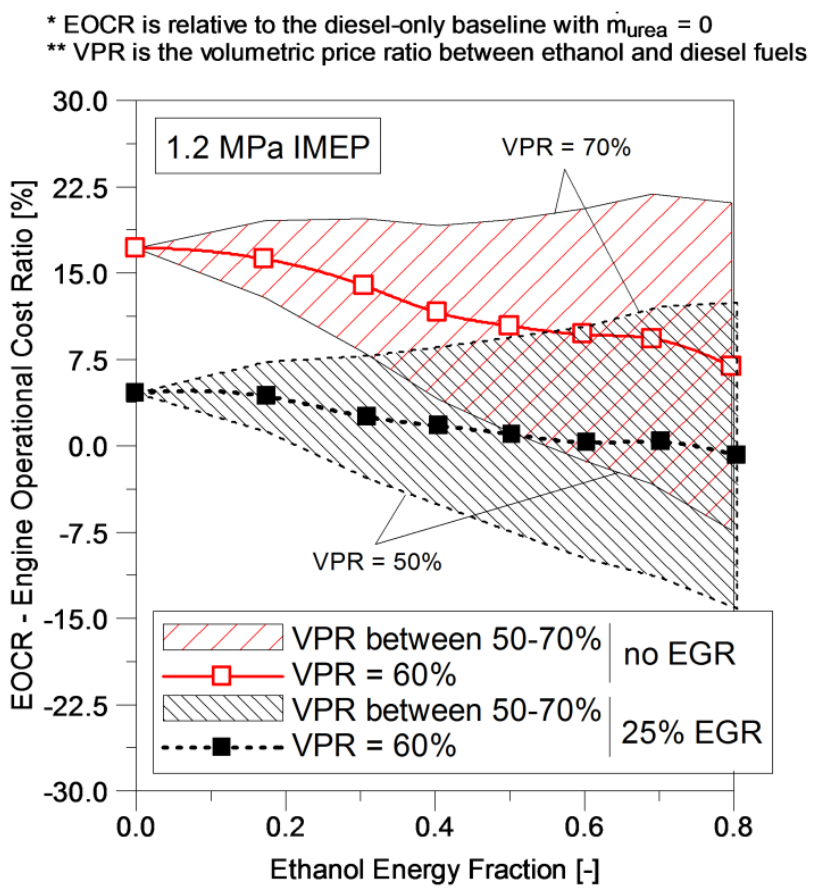

Figure 12 - Sensitivity of the EOCR to different volumetric price ratios between ethanol and diesel fuels. 
The results highlight the potential of high ethanol energy fractions and a moderate EGR rate to reduce the overall engine running costs via lower consumption of aqueous urea solution. This demonstrates the optimum balance between in-cylinder and aftertreatment control of NOx emissions. However, the effectiveness of dual-fuel combustion in terms of cost heavily depends on fuel prices, which vary according to availability of feedstock, production process, financial incentives, supply obligations, etc. Dual-fuel combustion will reduce the engine operational cost when the $V P R$ between ethanol and diesel fuels is at most $60 \%$. Higher relative prices can still be cost-effective depending on the EGR rate and ethanol fraction.

\section{Conclusions}

In this study, engine experiments were carried out to explore the potential of ethanol-diesel dualfuel combustion at $0.9,1.2$, and 1.5 MPa IMEP. The investigation was performed on a single cylinder heavy-duty diesel engine using $0 \%$ and $25 \%$ EGR. Diesel injection timings were optimised for the maximum efficiency while varying the ethanol energy fraction. Combustion characteristics, exhaust emissions, and performance of the most efficient cases were discussed. Cost-benefit ratio and overall exhaust emissions aspects of the utilisation of ethanol and EGR were introduced. The primary findings can be summarised as follows:

- Dual-fuel combustion with premixed ethanol fuel ignited by a single diesel injection near TDC limited the engine operating range due to excessive pressure rise rates. Alternatively, the use of a pre-injection in conjunction with the main diesel injection reduced the levels of PRR and was a key enabler for achieving efficient mid-load dual-fuel combustion with ethanol energy fractions up to $80 \%$.

- The increase in engine load from 0.9 to $1.5 \mathrm{MPa}$ IMEP in dual-fuel mode led to earlier ignition of the premixed ethanol and shorter combustion durations. This required retarded diesel injection timings to lower the in-cylinder pressure rise rates. 
- Higher ethanol percentages reacted similarly to the effect of increased load, resulting in faster burn durations and requiring later diesel injection timings. Despite the retarded combustion, net indicated efficiency was maintained essentially constant due the more thermodynamically optimum heat release.

- Ethanol-diesel dual-fuel combustion achieved high efficiency along with low NOx emissions. High ethanol energy fractions reduced the ISNOx levels of conventional diesel combustion by up to $68 \%$ at the expense of higher ISCO and ISHC.

- The use of $25 \%$ EGR was effective in reducing NOx emissions by approximately $80 \%$ with negligible impact on the indicated efficiency compared to the cases without EGR at the same ethanol energy fraction. This improvement minimised the estimated aqueous urea solution flow rate in the SCR system and consequently the running costs.

- The engine operational cost is highly dependent on fuel prices despite the significant NOx reduction capability and lower aqueous urea solution consumption attained with ethanoldiesel dual-fuel combustion.

\section{Acknowledgments}

V. Pedrozo would like to acknowledge CAPES Foundation - Ministry of Education of Brazil for supporting his PhD study at Brunel University London under the supervision of Prof. Zhao.

\section{References}

[1] Exxon Mobil Corporation. The Outlook for Energy: A View to 2040. Irving, Texas: 2016.

[2] Posada F, Chambliss S, Blumberg K. Costs of emission reduction technologies for heavyduty diesel vehicles. Washington, DC: The International Council on Clean Transportation; 2016. 
[3] Delgado O, Lutsey N. The U.S. SuperTruck Program: Expediting the development of advanced heavy-duty vehicle efficiency technologies. Washington, DC: International Council on Clean Transportation; 2014.

[4] Charlton S, Dollmeyer T, Grana T. Meeting the US Heavy-Duty EPA 2010 Standards and Providing Increased Value for the Customer. SAE International Journal of Commercial Vehicles 2010;3. doi:10.4271/2010-01-1934.

[5] Johnson T V. Diesel Emissions in Review. SAE International Journal of Engines 2011;4. doi:10.4271/2011-01-0304.

[6] Stanton DW. Systematic Development of Highly Efficient and Clean Engines to Meet Future Commercial Vehicle Greenhouse Gas Regulations. SAE International Journal of Engines 2013;6. doi:10.4271/2013-01-2421.

[7] Reitz RD. Directions in internal combustion engine research. Combustion and Flame 2013;160:1-8. doi:10.1016/j.combustflame.2012.11.002.

[8] Pedrozo VB, May I, Dalla Nora M, Cairns A, Zhao H. Experimental analysis of ethanol dualfuel combustion in a heavy-duty diesel engine: An optimisation at low load. Applied Energy 2016;165:166-82. doi:10.1016/j.apenergy.2015.12.052.

[9] Pedrozo V, May I, Zhao H. Characterization of Low Load Ethanol Dual-Fuel Combustion using Single and Split Diesel Injections on a Heavy-Duty Engine. SAE Technical Paper 2016. doi:10.4271/2016-01-0778.

[10] Han X, Zheng M, Tjong J. Clean combustion enabling with ethanol on a dual-fuel compression ignition engine. International Journal of Engine Research 2015:1-13. doi:10.1177/1468087415575646. 
[11] Divekar P, Yang Z, Ting D, Chen X, Zheng M, Tjong J. Efficiency and Emission Trade-Off in Diesel-Ethanol Low Temperature Combustion Cycles. SAE Technical Paper 2015. doi:10.4271/2015-01-0845.

[12] Heuser B, Kremer F, Pischinger S, Rohs H, Holderbaum B, Körfer T. An experimental investigation of dual-fuel combustion in a light duty Diesel engine by in-cylinder blending of ethanol and Diesel. SAE Technical Paper 2015. doi:10.4271/2015-01-1801.

[13] Divekar PS, Asad U, Tjong J, Chen X, Zheng M. An engine cycle analysis of diesel-ignited ethanol low-temperature combustion. Proceedings of the Institution of Mechanical Engineers, Part D: Journal of Automobile Engineering 2015. doi:10.1177/0954407015598244.

[14] Chen Z, Liu J, Wu Z, Lee C. Effects of port fuel injection (PFI) of n-butanol and EGR on combustion and emissions of a direct injection diesel engine. Energy Conversion and Management 2013;76:725-31. doi:10.1016/j.enconman.2013.08.030.

[15] Tutak W. Bioethanol E85 as a fuel for dual fuel diesel engine. Energy Conversion and Management 2014;86:39-48. doi:10.1016/j.enconman.2014.05.016.

[16] Sarjovaara T, Larmi M. Dual fuel diesel combustion with an E85 ethanol/gasoline blend. Fuel 2015;139:704-14. doi:10.1016/j.fuel.2014.09.049.

[17] Sarjovaara T, Larmi M, Vuorinen V. Effect of charge air temperature on E85 dual-fuel diesel combustion. Fuel 2015;153:6-12. doi:10.1016/j.fuel.2015.02.096.

[18] Asad U, Kumar R, Zheng M, Tjong J. Ethanol-fueled low temperature combustion: A pathway to clean and efficient diesel engine cycles. Applied Energy 2015. doi:10.1016/j.apenergy.2015.01.057. 
[19] Kokjohn SL, Hanson RM, Splitter D a, Reitz RD. Fuel reactivity controlled compression ignition (RCCl): a pathway to controlled high-efficiency clean combustion. International Journal of Engine Research 2011;12:209-26. doi:10.1177/1468087411401548.

[20] Reitz RD, Duraisamy G. Review of high efficiency and clean reactivity controlled compression ignition (RCCl) combustion in internal combustion engines. Progress in Energy and Combustion Science 2015;46:12-71. doi:10.1016/j.pecs.2014.05.003.

[21] Kokjohn SL, Musculus MPB, Reitz RD. Evaluating temperature and fuel stratification for heat-release rate control in a reactivity-controlled compression-ignition engine using optical diagnostics and chemical kinetics modeling. Combustion and Flame 2015;162:2729-42. doi:10.1016/j.combustflame.2015.04.009.

[22] Desantes JM, Benajes J, García A, Monsalve-Serrano J. The role of the in-cylinder gas temperature and oxygen concentration over low load reactivity controlled compression ignition combustion efficiency. Energy 2014;78:854-68. doi:10.1016/j.energy.2014.10.080.

[23] Benajes J, García A, Monsalve-Serrano J, Boronat V. Achieving clean and efficient engine operation up to full load by combining optimized $\mathrm{RCCl}$ and dual-fuel diesel-gasoline combustion strategies. Energy Conversion and Management 2017;136:142-51. doi:10.1016/j.enconman.2017.01.010.

[24] Asad U, Zheng M. Exhaust gas recirculation for advanced diesel combustion cycles. Applied Energy 2014;123:242-52. doi:10.1016/j.apenergy.2014.02.073.

[25] Asad U, Zheng M, Tjong J. Experimental Investigation of Diesel-Ethanol Premixed PilotAssisted Combustion (PPAC) in a High Compression Ratio Engine. SAE International Journal of Engines 2016;9. doi:10.4271/2016-01-0781. 
[26] Hanson R, Ickes A, Wallner T. Comparison of RCCI Operation with and without EGR over the Full Operating Map of a Heavy-Duty Diesel Engine. SAE Technical Paper 2016. doi:10.4271/2016-01-0794.

[27] May I, Pedrozo V, Zhao H, Cairns A, Whelan S, Wong H, et al. Characterization and Potential of Premixed Dual-Fuel Combustion in a Heavy Duty Natural Gas/Diesel Engine. SAE Technical Paper 2016. doi:10.4271/2016-01-0790.

[28] Heywood JB. Internal Combustion Engine Fundamentals. 1st ed. McGraw-Hill, Inc.; 1988.

[29] Silvis WM. An Algorithm for Calculating the Air/Fuel Ratio from Exhaust Emissions. SAE Technical Paper 1997. doi:10.4271/970514.

[30] Wallner T. Correlation Between Speciated Hydrocarbon Emissions and Flame Ionization Detector Response for Gasoline/Alcohol Blends. Journal of Engineering for Gas Turbines and Power 2011;133. doi:10.1115/1.4002893.

[31] Kar K, Cheng WK. Speciated Engine-Out Organic Gas Emissions from a PFI-SI Engine Operating on Ethanol/Gasoline Mixtures. SAE International Journal of Fuels and Lubricants 2009;2. doi:10.4271/2009-01-2673.

[32] Pedrozo VB, May I, Lanzanova TDM, Zhao H. Potential of internal EGR and throttled operation for low load extension of ethanol-diesel dual-fuel reactivity controlled compression ignition combustion on a heavy-duty engine. Fuel 2016;179:391-405. doi:10.1016/j.fuel.2016.03.090.

[33] Zhao H. HCCl and CAl engines for automotive industry. Cambridge: Woodhead Publishing Limited; 2007.

[34] Zhao H. Advanced direct injection combustion engine technologies and development Volume 2: Diesel engines. Cambridge: Woodhead Publishing Limited; 2010. 
[35] Gao T, Jeftic M, Bryden G, Reader G, Tjong J, Zheng M. Heat Release Analysis of Clean Combustion with Ethanol Ignited by Diesel in a High Compression Ratio Engine. SAE Technical Paper 2016. doi:10.4271/2016-01-0766.

[36] Baumgarten C. Mixture formation in internal combustion engines. Springer-Verlag Berlin Heidelberg; 2006.

[37] Economic Commission for Europe of the United Nations (UN/ECE). Regulation No 49 Uniform provisions concerning the measures to be taken against the emission of gaseous and particulate pollutants from compression-ignition engines and positive ignition engines for use in vehicles. Official Journal of the European Union 2013.

[38] Prikhodko VY, Curran SJ, Parks JE, Wagner RM. Effectiveness of Diesel Oxidation Catalyst in Reducing $\mathrm{HC}$ and $\mathrm{CO}$ Emissions from Reactivity Controlled Compression Ignition. SAE International Journal of Fuels and Lubricants 2013;6. doi:10.4271/2013-01-0515.

[39] Schaefer M, Hofmann L, Girot P, Rohe R. Investigation of NOx- and PM-reduction by a Combination of SCR-catalyst and Diesel Particulate Filter for Heavy-duty Diesel Engine. SAE International Journal of Fuels and Lubricants 2009;2. doi:10.4271/2009-01-0912.

[40] Johansen K, Widd A, Truck M a N, Ag B. Passive NO2 Regeneration and NOx Conversion for DPF with an Integrated Vanadium SCR Catalyst. SAE Technical Paper 2016. doi:10.4271/2016-01-0915.

[41] Benajes J, García A, Monsalve-Serrano J, Balloul I, Pradel G. An assessment of the dualmode reactivity controlled compression ignition/conventional diesel combustion capabilities in a EURO VI medium-duty diesel engine fueled with an intermediate ethanol-gasoline blend and biodiesel. Energy Conversion and Management 2016;123:381-91. doi:10.1016/j.enconman.2016.06.059. 